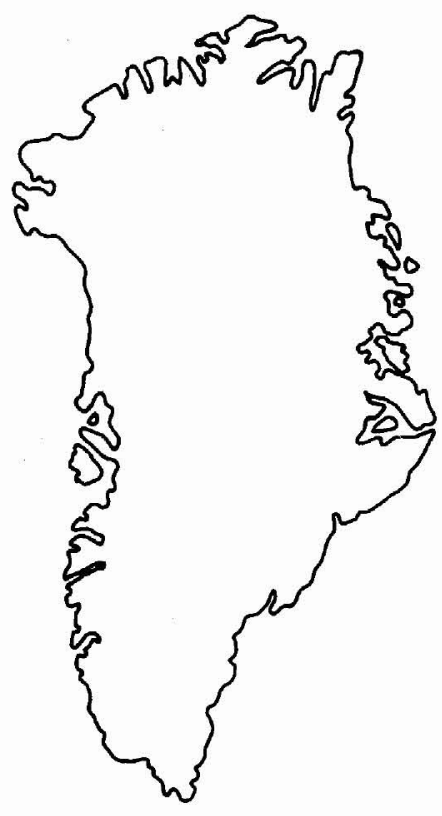

\title{
Shape and size of lacustrine deposited melanogen (opaque organic matter), Upper Carboniferous, East Greenland
}

\author{
Torsten Hoelstad, Stefan Piasecki and Lars Stemmerik
}

\begin{abstract}
The content of opaque particles (melanogen) in eight kerogen concentrates from lacustrine sediments of the Upper Carboniferous of East Greenland are characterized with respect to shape and size by means of electronic image analysis.

The method of electronic image analysis is briefly described and the applied sequence of image analysis functions is explained. The main items of the program sequence are shade and intensity correction, object discrimination and object selection. It is demonstrated that the method produces consistent results. Shape indices for circularity ( $4 \pi \times$ area/perimeter $\left.{ }^{2}\right)$ and elongation $\left((\mathrm{b} / \mathrm{a})^{1 / 2}\right)$ and the areas of the optical sections have been recorded. These parameters have a distinct relationship to the sedimentary environment; the melanogen particles in the clay-siltstone beds show increasing circularity, decreasing elongation and increasing areas up through the coarsening-upward sequences. Thus, the size and shape of the melanogen particles are not only tied to the sedimentary texture of the actual sample, but also to the overall textural characteristics of the section.
\end{abstract}

T. H., Geological Survey of Denmark, Thoravej 8, DK-2400 Copenhagen NV, Denmark.

S. P. \& L. S., Geological Survey of Greenland, Øster Voldgade 10, DK-1350 Copenhagen $K$, Denmark.

With the introduction of electronic image analysis, truly quantitative dimensions are added to palynofacies analysis (Hansen \& Clausen, 1987; Tyson, 1989, 1990; Hoelstad, 1988, 1989; Highton, 1990). The present study concerns the melanogen (opaque organic material) fraction, which is especially well suited for electronic image analysis because of the high contrast between particles and background.

Papers on palynofacies analysis primarily deal with the kerogen composition and rarely emphasize the textural aspects and, furthermore, when included the descriptions are entirely qualitative (examples are found in Fisher, 1980; Denison \& Fowler, 1980; Parry et al., 1981; Tyson, 1984, 1987; Whittaker, 1984; Hoelstad, 1986). The reason for the qualitative approach is technical, as a manual quantitative textural analysis of kerogen concentrates in standard palynological preparations is time consuming and in practice unrealistic. Electronic image analysis solves this problem, and the textural properties can be determined based on statistically valid sample sizes and thus be utilized with much more confidence in palynofacies analysis.

The purposes of the present investigation are to present the potential of electronic image analysis with regard to textural descriptions of the melanogen fraction of kerogen concentrates and to relate melanogen textural properties to the sedimentology.

\section{Geological setting}

The analysed material is from the upper part of an approximately 15 metres thick lacustrine sequence in the Upper Carboniferous sediments exposed at Kongeborgen, Traill $\varnothing$, East Greenland (Fig. 1).

The entire Carboniferous-Lower Permian succession reaches a cumulative thickness of approximately $3 \mathrm{~km}$ in central East Greenland. The sediments were deposited in a system of rotated half-grabens. During the Late Carboniferous coarse-grained sediments were deposited in alluvial fan and braid-plain environments along the western basin margin (Stemmerik et al., 1990). These sediments pass eastwards into more fine-grained flood plain deposits. Lacustrine sediments occur interbedded with the coarse-grained deposits along the western basin margin. The lacustrine succession at Kongeborgen consists of grey to black siltstones and mudstones with a high organic content in combination with high Hydrogen Index (HI) values (Piasecki et al., 1990). It is divided into a 


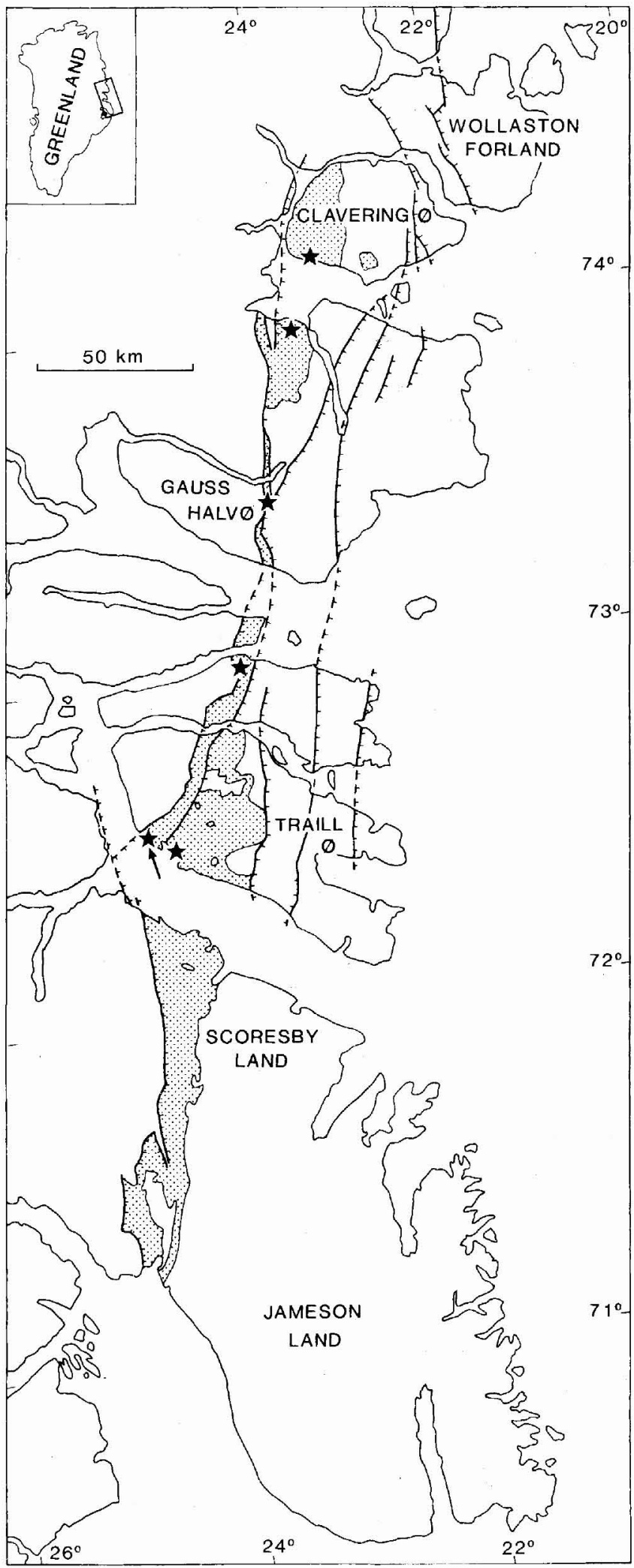

Fig. 1. Map of central East Greenland showing the distribution of Carboniferous - Lower Permian sediments. Position of the Kongeborgen section is indicated by an arrow. Stars mark other locations with lacustrine sediments. 


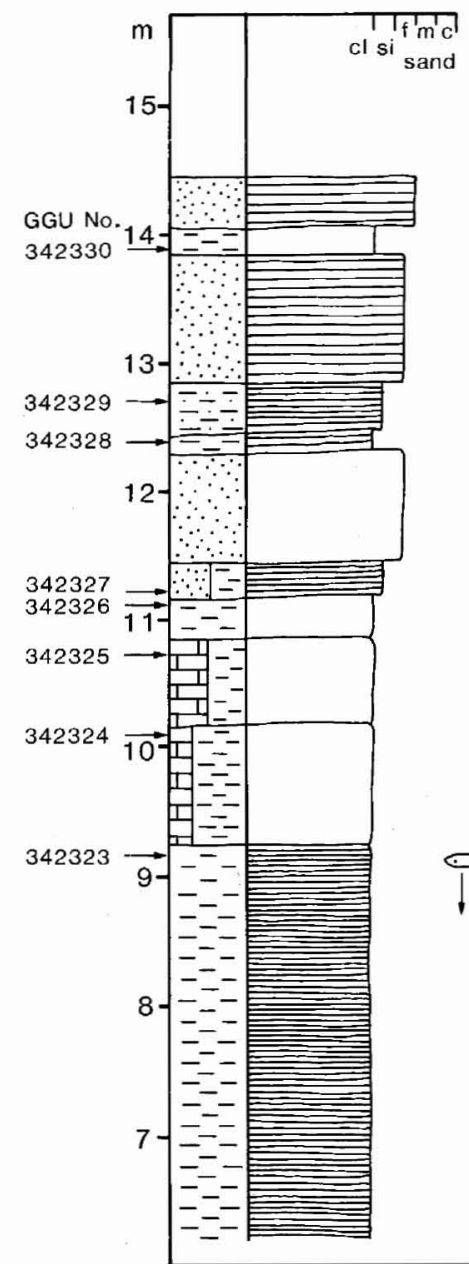

LITHOLOGY

-_- Mudstone

$\dot{\overline{-} \div}$ Clay-Siltstone

$\because \because \vdots$ Sandstone
$\because \because \because 1$
$\square$ Carbonate

STRUCTURE

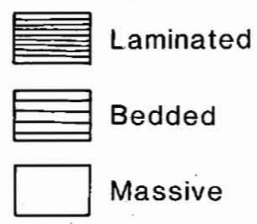

RATIO OF SPORES \&

COMPOSITION POLLEN (\%)

$$
\text { OF THE ORGANIC MATTER (\%) }
$$

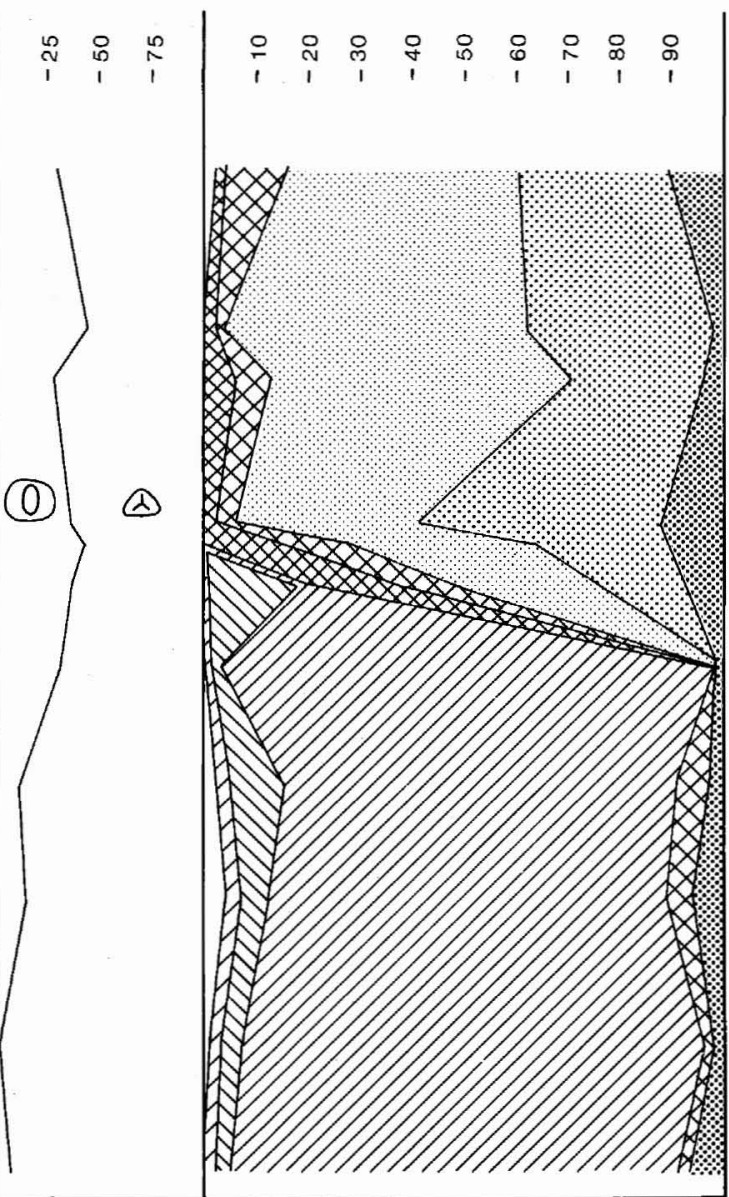

FOSSILS

(8) Plant fragments

$œ$ Fish

$\Leftrightarrow$ Ostracods

(A) Spores

(0) Pollen

$1 / 1$ Botryococcus

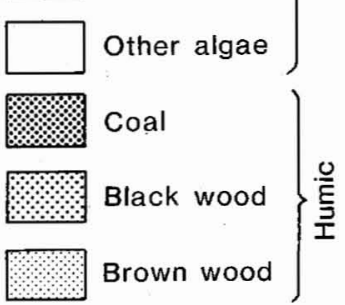




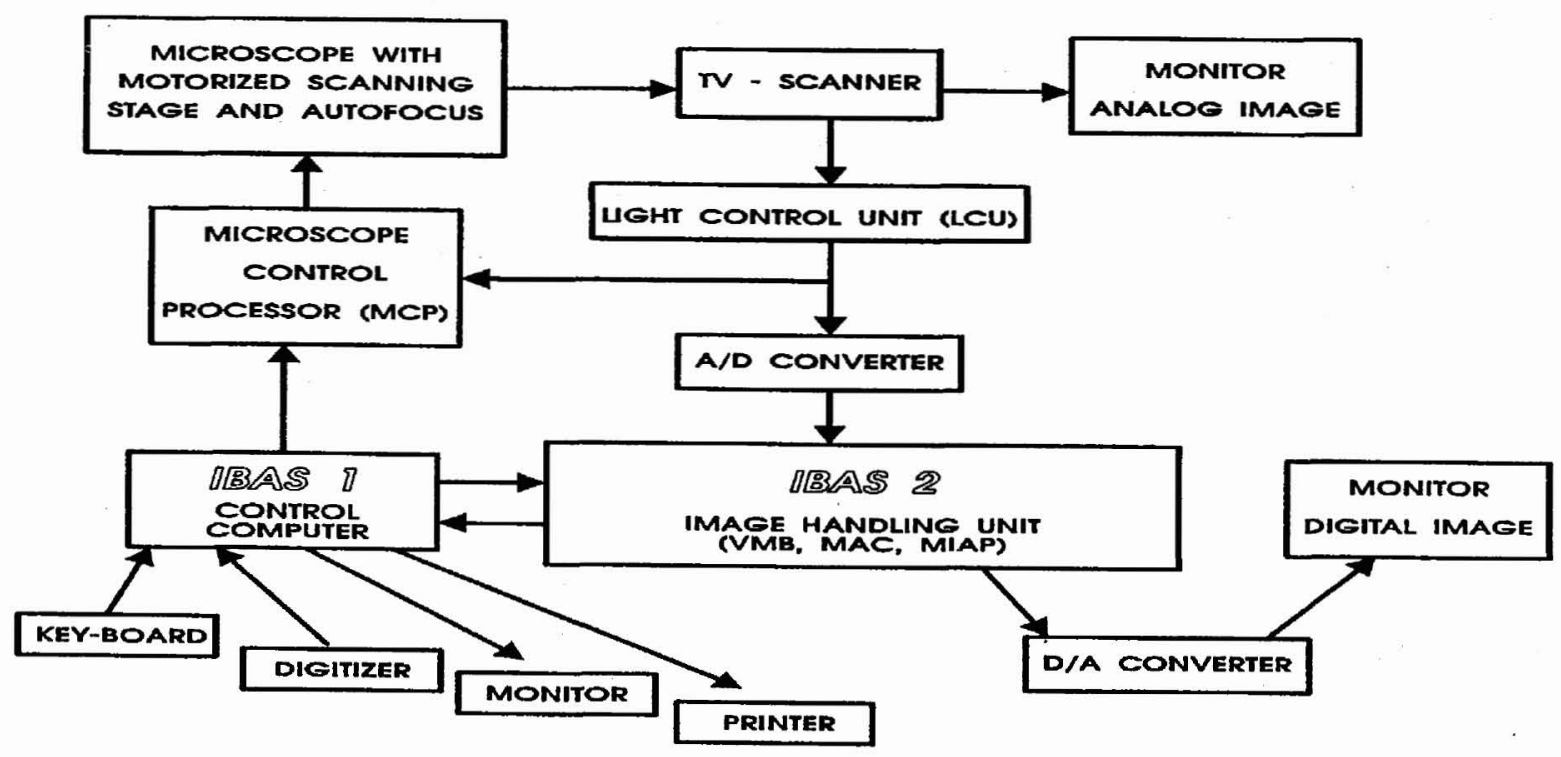

Fig. 3. Simplified block diagram of the IBAS image analysis system.

hypolimnic facies $(0-c .10 .50 \mathrm{~m})$ and an epilimnic facies (c. $10.50-14.40 \mathrm{~m}$ ) on the basis of sedimentology, palynology and geochemistry (Fig. 2; Piasecki et al., 1990).

The hypolimnic facies are characterized by black, calcareous shales with a high organic content and frequent fossilized faunas of freshwater fish and ostracods. The primary lamination of the shales is defined by variation in the content of clay, silt-sized mica and carbonate. The organic material is dominated by amorphous kerogen (80-90\%) with degraded Botryococcus colonies and locally a few other algae (Fig. 2). Sporomorphs are rare with trilete spores dominating (80-90\%) over monosaccate pollen. Terrestrial derived organic matter of brown and black woody material (melanogen) is of minor importance. The hypolimnic sediments were deposited in the deepest part of the lake with low to zero oxygen levels in the bottom water and sediments. The organic matter is classified as Type I/II kerogen with good potential as a source rock for liquid hydrocarbons.

The epilimnic unit comprises coarser sediments. Grey, laminated to cross-laminated siltstones with a very high content of mica and coalified wood are followed by fineto medium-grained, laminated sandstones in $1.5-2.0 \mathrm{~m}$ thick coarsening-upward sequences (Fig. 2). Fish and ostracods are absent but plant fragments are common. The content of organic matter is low to high $(1-7 \%)$ but with constantly low HI values (average 37 ) because woody material and coaly fragments comprise $80-90 \%$ of the organic material. The monosaccate pollen make up $40-50 \%$ of the sporomorphs compared to $10-20 \%$ in the hypolimnic association. Algal remains are rare (Fig. 2). The organic matter is classified as Type III kerogen with potential for gas only. The sediments were deposited in a shallow well-oxygenated environment in front of small prograding deltas. The coarsening-upwards sequences are interpreted to represent prograding mouth bars in front of rivers that gradually filled the lake with sediments.

Thus, these epilimnic sediments are interpreted to record simple fluvial infilling of a deep anoxic lake which was tectonically induced (Piasecki et al., 1990). The depositional history is closely reflected in the composition and preservation of the organic content (Piasecki et $a l ., 1990)$ and the material was therefore considered excellent for further studies of the variation in the organic content by electronic image analysis.

\section{Electronic image analysis}

The image analysis system adopted is the IBAS 2 (manufacturer Kontron Bildanalyse $\mathrm{GmbH}$ ). The IBAS image analysis is a two processor system with a serial microcomputer as the control unit and an array processor as the image handling unit. The image handling unit consists of a $2 \mathrm{Mb}$ image memory (VMB), a memory address controller (MAC) and a 10 MIPS microprogrammable array processor (MIAP).

The image analysis configuration is shown in Fig.3. The analogous signal generated in the TV-scanner (Bosch) mounted on the microscope (Zeiss universal) is digitized in the analog/digital (A/D) converter and stored in the VMB with a spatial resolution of $512 \times 512$ pixels and a grey value resolution of 8 bit (256 grey values). The stored images can be displayed on a conventional monitor via the $\mathrm{D} / \mathrm{A}$ converter. The image manipulation is 
carried out by microprogram orders and microprogram sequences selected from the control computer. The programming is menu-driven and is controlled via the keyboard or the digitizer tablet. The microscope is equipped with a motorized scanning table, a light intensity based autofocus unit and a feedback light control unit.

\section{Image analysis sequence}

The image analysis sequence can be subdivided into four main routines. These are calibration, enhancement and segmentation, particle selection and measuring (Fig. 4).

Before an analysis is initiated, the system must be calibrated. The various buffers are cleared and the appropriate micrometer to pixel conversion factor is selected. For the $\times 10$ objective used in the present investigation, the conversion factor is 1.195 micrometer/pixel. The sample is then labelled using the preparation and slide identification code. A measuring frame is introduced in order to achieve equal size fraction representation. The microscope scanning table is set to a predefined position - the position of origin $(0,0,0)$ - chosen as the upper right corner of the cover glass. The scanning table is then moved to the first field of view in the meander path and the autofocus is initialized.

To reduce the effect of TV-scanner artifacts (noise) three images of the actual field of view are digitized and stored and the average image is computed. Microscopes in general do not produce evenly illuminated fields of view, thus an electronic illumination correction (shading) is necessary. A prerequisite for this correction is knowledge about the grey value distribution of the entire background. A simple way of obtaining that information is to record an empty field of view. When considering palynological preparations, however, this method is inadequate because every field of view has particular background characteristics due to thickness differences in the embedding medium, differences in focus levels and influence from particles that are severely out of focus. The background grey value distribution is reconstructed by applying an electronic filter in order to eliminate the particles and overwrite them with interpolated background values. By setting grey value thresholds a rough discrimination of the background is achieved. The maximum grey value for pixels defined as particles is 199 , thus the background covers the grey value interval 200 255 . The thresholds need to be set only once as the light control unit ensures the adequate light intensity. A matrix of the size $255 \times 255$ (sufficiently larger than the expected largest particle) is applied to every pixel and whenever the central pixel of the matrix belongs to a particle its grey value is substituted with that of the pixel in the upper right corner of the matrix. This operation is succeeded by a $255 \times 1$ average filter (lowpass) to balance out possible discontinuities. Dividing the original
GARURRAIION

EINIIANCEMTENT \& SEGMOEMTATION

PARITCLE SELECUDON

MIEASURUNE

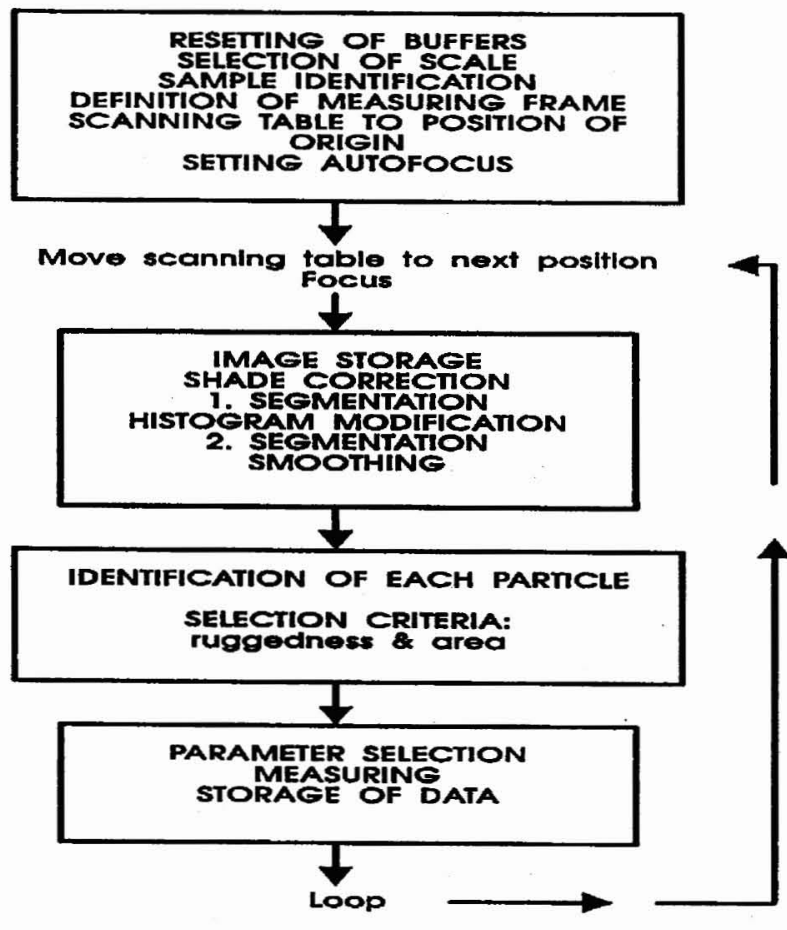

Fig. 4. The image analysis sequence. 


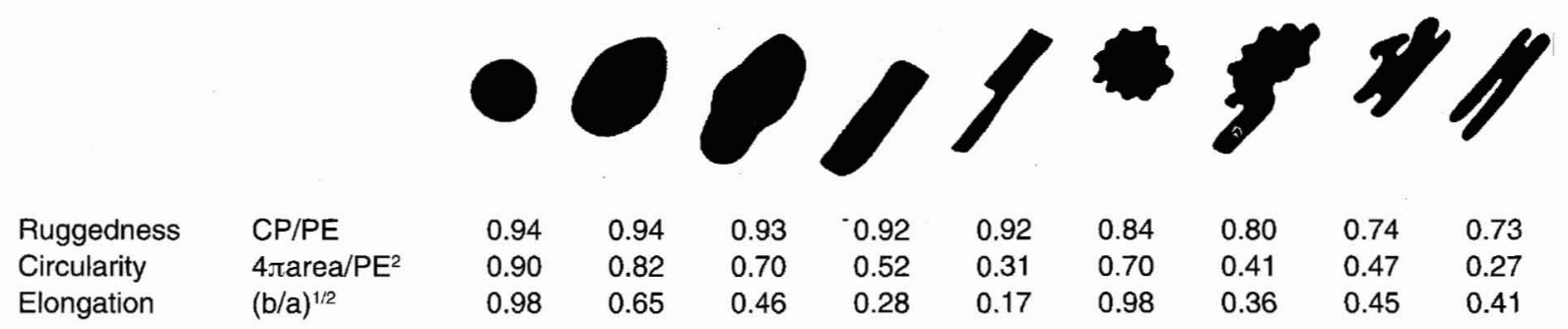

Fig. 5. Particle shapes and their corresponding indices. $\mathrm{CP}=$ convex perimeter, $\mathrm{PE}=$ perimeter, $\mathrm{a}$ and $\mathrm{b}=$ areal principal moments.

image by the background reference and multiplying with a fixed value (255) results in grey values in the vicinity of 255 for all background pixels and consequently corrected particle grey values. Besides the shade correction the method provides a grey value calibrated image, and, therefore, minor fluctuations in the light intensity are of no consequence.

The next step is to define a suitable grey value range which includes all the darkest particles. The interval 0-50 omits none of the desired particles. The segmentation converts the background grey values to black $(0)$ but leaves the particle grey values $(0-50)$ intact. In order to increase the contrast the grey values are linearly transformed to occupy the entire grey level range (0-255). It is now possible to carry out the final segmentation, which leads to the binary image. The reasons for the linear transformation of the grey value histogram are that the absolute threshold setting becomes less sensitive and that elimination of stray light or edge effects becomes possible. The final threshold values are 1 and 225. A rank order filter is applied to the binary image in order to smooth particle edges, thus emphasizing the overall shape characteristics and eliminating small edge irregularities. The rank order filter employs a $3 \times 3$ matrix and at every position the central pixel is exchanged for the pixel with the seventh highest value. In a binary image this means that besides being smoothed the particle areas (white areas) increase. The filter is chosen in that way to compensate for the area loss caused by edge effects in the segmentation process.

The binary image is the basis for the measurement, but each particle must be defined as an entity. This involves the use of a connectivity rule which states that all image object pixels are connected in eight directions whereas background pixels are connected in four directions only. In this way the individual particles are identified and in practice given separate grey values. The identification concerns all true black particles, although these consist of several different kerogen type fractions, e.g. superimposed palynomorphs, inertinite rich amorphous aggregates and aggregates of two or more melanogen particles. The irregularity or ruggedness of the particle circumfer-

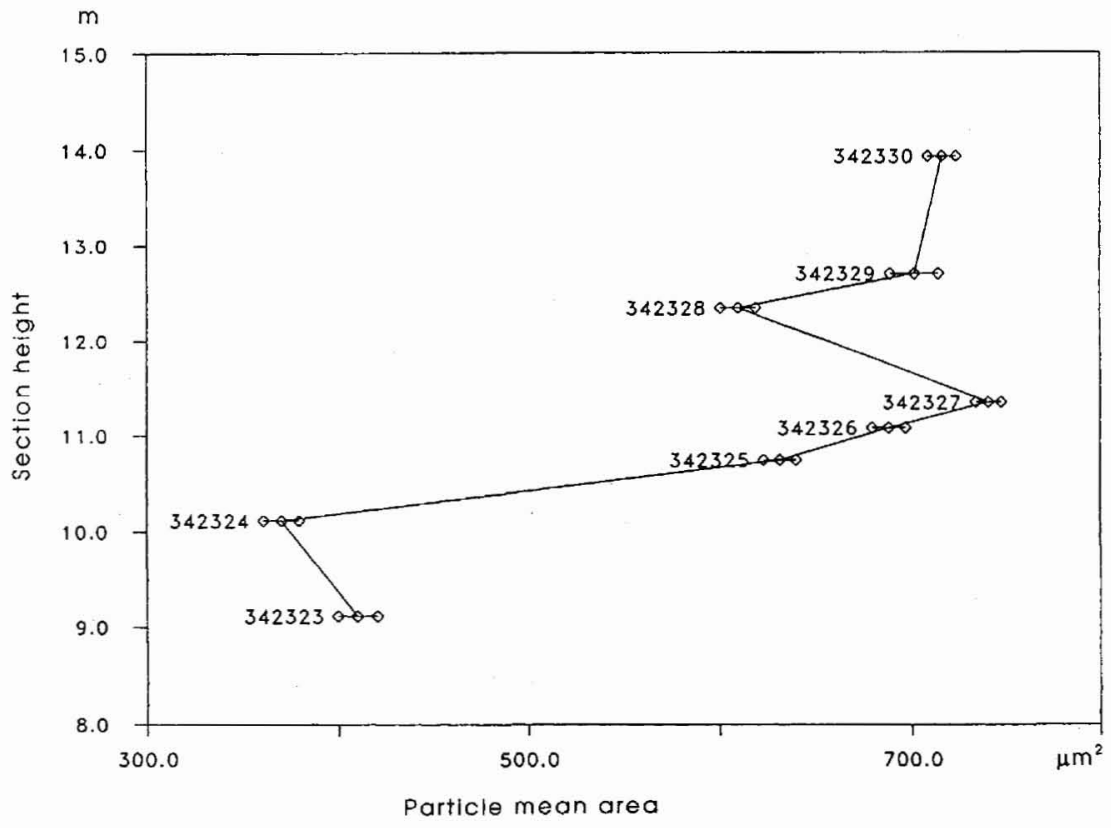

Fig. 6. Geometric means of melanogen particle area projections from the Kongeborgen section. Horizontal bars indicate the $90 \%$ probability intervals. 
Fig. 7. Geometric standard deviations of melanogen particle area projections from the Kongeborgen section. Horizontal bars indicate the $90 \%$ probability intervals.

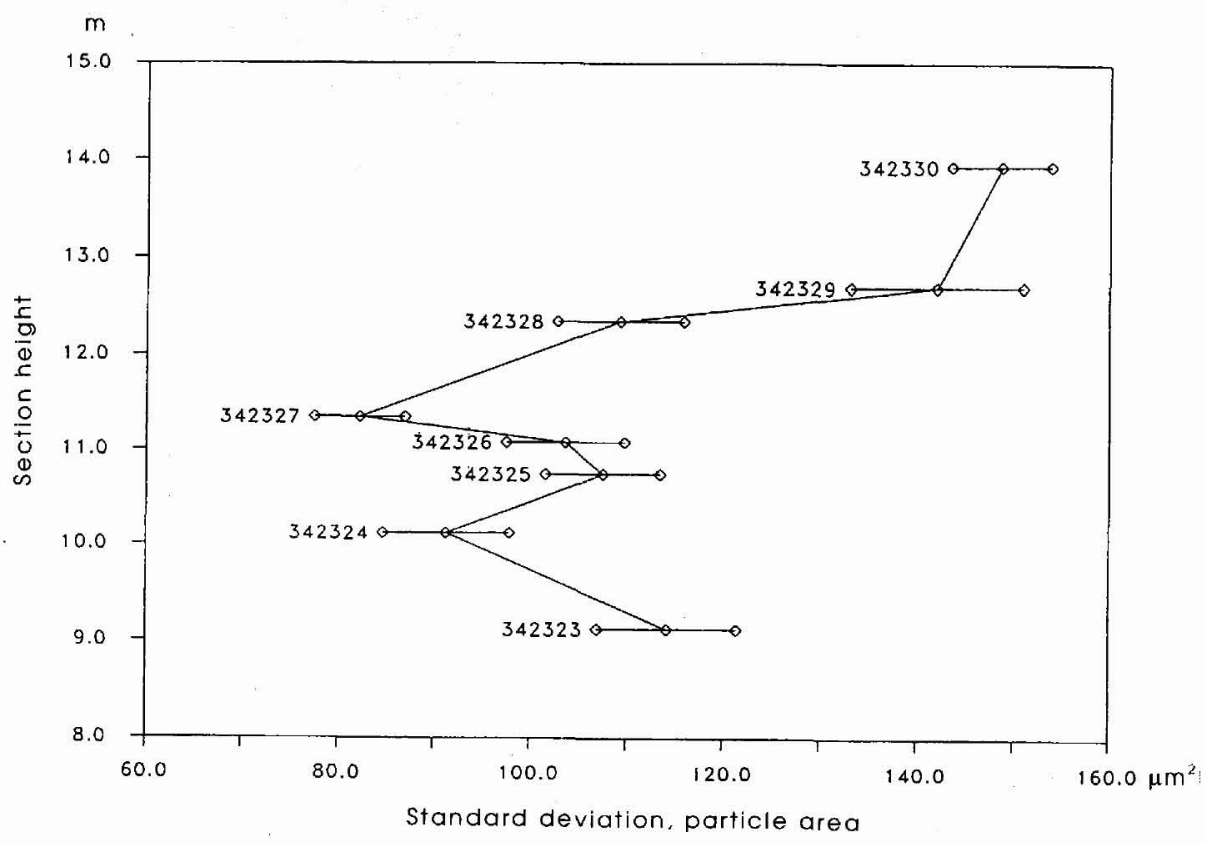

ence is used as a selection criterium. The relation of the convex perimeter (CP) to the actual perimeter (PE) expressed as the ratio $\mathrm{CP} / \mathrm{PE}$ is effective when sorting out true simple-shaped melanogen particles. A 0.85 threshold has been established empirically. Examples of various particle shapes and their ruggedness indices are given in Schwartz (1980) and on Fig.5. Owing to the chosen objective $(\times 10)$, measurements of particles less than 150 square micron will reflect resolution rather than textural characteristics and particles larger than 5000 square micron will seldom be entirely contained in the field of view. Thus only the area interval 150-5000 square micron is considered. The ruggedness and area criteria are implemented via a measurement procedure, which eliminates the particles not fulfilling either of the criteria.

The final steps of the image analysis sequence are definition of the measuring parameters (two shape indices and the area), the actual measurement, the data storage and the data treatment.

\section{Particle size and shape}

Textual characteristics are best expressed in three dimensions.

When dealing with palynological preparations, however, the opaque particles are only represented by projections of their outlines and the sizes and shapes are thus dependent on the spatial orientation of the particles in the embedding medium. Due to generic and compressional factors the melanogen fraction is dominated by platy to bladed particle types, i.e. the short dimension is much smaller than the other two. The effect is that during the preparation process, when the particles are settling in the embedding medium, the short diameter will most likely be perpendicular to the cover glass. This means that the projected outlines most likely are maximum projections. All measurements refer to these projections and hence are subject to certain limitations (Russ, 1986), especially concerning concavities on particle surfaces and with regard to overlapping particles.

The areas of the particle projections are, under the assumption of a constant particle thickness, directly proportional to the particle volume. Although the validity of the assumption has not been tested, the mere volume might, from a hydraulic sorting point of view, be of lesser importance compared to the maximum projected area.

The sizes of the particle area projections are measured in square microns. The size distribution parameters are derived from the common logarithm representation of the distribution (geometric mean and geometric standard deviation). The shape indices measured are expressions of circularity and elongation (Fig. 5). The circularity index is defined as $\left(4 \pi \times\right.$ area/perimeter $\left.{ }^{2}\right)$. The circularity index equals unity for circles, for all other shapes it is less than unity. The index increases with increasing roundness and smoothness and thus it does not distinguish between elongated and rugged, more rounded particles (Schwartz, 1980). The elongation index is defined as the square root of the ratio between the areal principal moments, (b/a) ${ }^{1 / 2}$ (Medalia, 1967; Schwartz, 1980). The elongation index takes a value of unity for all equiaxial particles (e.g. circles and squares) and values less than unity for all 

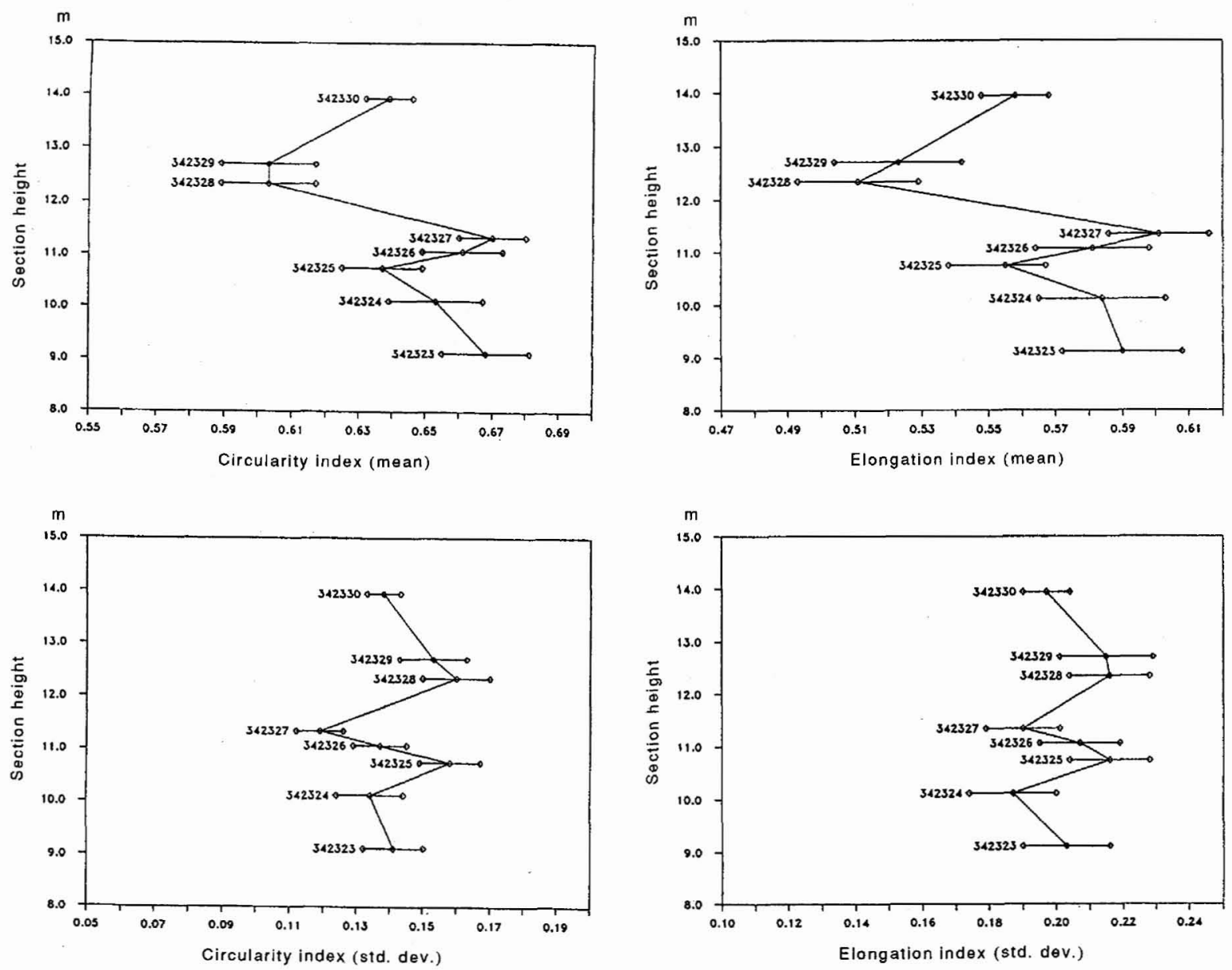

Fig. 8. Arithmetric means and standard deviations of particle shape indices for circularity and elongation from the Kongeborgen section. Horizontal bars indicate the $90 \%$ probability intervals.

other shaped particles, the smallest values representing the longest particles. The shape distribution parameters are calculated based on the arithmetric representation of the distribution.

\section{Measuring procedure}

Depending on the opaque particle density in the preparations, 50 to over 100 fields of view have been analyzed for each sample. In order to avoid bias with regard to particle size due to edge effects, a measuring frame was used. The measuring frame occupies an area of $412 \times 412$ pixels and is displaced in the total visible field leaving a 10 pixel margin along the right and upper sides. The margins along the left and lower sides are 90 pixels or $1.195 \times 90=c .108$ microns wide. This means that particles touching the left and lower edges of the measuring frame can have a maximum dimension of $c .108$ microns and yet be fully contained in the total visible field. When measuring a field of view only those particles which lie inside the measuring frame or are cut by the lower and left edges respectively are taken into account. Thus, the greater probability of the larger particles being cut by any edge is corrected for. In addition, the probability of recording particles truncated by the edge of the total visible field is greatly reduced. The size of the measuring frame is chosen such that particles in the upper range of the defined area interval (150-5000 square microns) are only eliminated in extreme cases.

The palynological preparations are scanned from the upper left to the lower right. Initially, ten successive measuring frames in the right hand direction are analysed, then the scanning table is moved five frames down, the next ten frames are analysed and so on. When reaching the lower right of the preparation the scanning table moves to a position one frame left and one frame below the initial position and a parallel path is followed. By scanning diagonally possible inhomogenities in the preparation are averaged. 


\section{Sources of error and statistical treatment}

Errors which will typically affect the geometry of the particle projections are those introduced by the slightly rectangular pixels, the various electronic filters, the segmentation process, the grey histogram modifications and by noise. These errors will cause differences between two identical runs of the same sample. The order of magnitude of this difference is $1 \%$ based on two runs covering the same 42 fields of view.

The major errors are those connected with estimation of the population parameters. Based on the standard error and a $10 \%$ significance level there is a $90 \%$ probability that the population mean lies within the interval: Sample mean $+/-$ - (critical value of $t$-distribution (1.65) $\times$ standard error). It is evident that the probability interval narrows when increasing the count (standard error = standard deviation/square root of the count). For practical reasons a minimum count of 200-300, given the order of magnitude of the standard deviations obtained in the present investigation, produces useful estimates i.e. statistically significant differences. The $90 \%$ probability interval for the standard deviation is calculated using the formula: Critical value of $t$-distribution (1.65) $\times$ estimate of standard deviation/square root of twice the count minus one. This is an approximation to the chi-square distribution based tolerance limits; however, given the number of degrees of freedom well above 200 , differences are negligible.

\section{Discussion}

The graph of the geometric means of the melanogen particle area projections shows that sizes are considerably smaller (around 400 square microns) in the hypolimnic samples than in the epilimnic samples (greater than 600 square microns) (Fig. 6). Differences between the hypolimnic and epilimnic sediments are not evident on the graphs showing the area geometric standard deviations (Fig. 7) or the shape parameters (Fig. 8).

Two coarsening-upward sequences are recognized in the epilimnic interval. The lower coarsening-upward sequence covers the interval from about $10.50 \mathrm{~m}$ to about $12.25 \mathrm{~m}$ (GGU samples 342325 to 342327 ) and the upper sequence the interval from about 12.25 to about $14.25 \mathrm{~m}$ (Fig. 2). The cycles are characterized by an upward transition from carbonaceous mudstone or mudstone via argillaceous siltstone to sandstone. Samples for palynology were taken exclusively in the finer grained sediments, and consequently the upper and coarse-grained portions of the coarsening-upward cycles are only represented where fine-grained interbeds are present (GGU sample 342330).

The geometric means of the melanogen particle area projections reflect the two coarsening-upward sequences very well (Fig. 6). With the exceptions of GGU samples 342329 and 342330 there are statistically significant differences between the samples in the two cycles. It is important to note that the geometric means of the melanogen particle area projections increase not only with increasing grain size in the actual samples (e.g. GGU sample 342328 (mudstone) to GGU sample 342329 (siltstone)) but also increase independently of the grain size of the actual samples in response to the overall textural trends. Examples are observed by comparing GGU sam-
Fig. 9. Plot of geometric means against geometric standard deviations for lacustrine deposited melanogen particle area projections from the Upper Carboniferous Kongeborgen section.

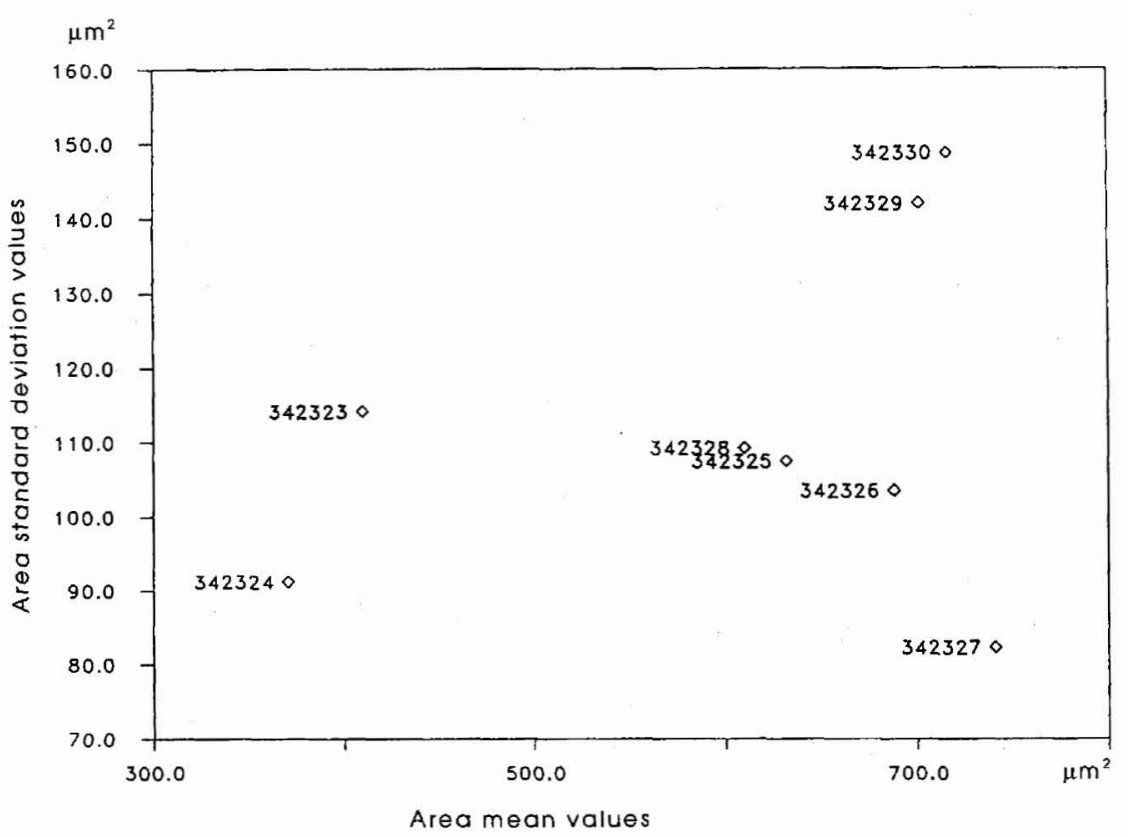


ple 342328 with GGU sample 342330 and GGU sample 342325 with GGU sample 342326 .

The shape indices of the projections also show a development that is in close accordance with the sedimentology. In the two coarsening-upward sequences the indices of both circularity and elongation increases upwards (Fig. 8). Thus in response to a coarser sedimentary texture the melanogen particles become more circular and less elongated. The standard deviations of the shape index distributions decrease upwards in each of the two coarsening-upward cycles. This indicates better sorted shape populations in the upper parts of the coarsening upward sequences.

Figures 7 and 9 show that the two coarsening-upward sequences differ with respect to the geometric standard deviation of the area projections. Given similar energy conditions, a likely explanation is a change in source area. This is further supported by differences in the shape indices between the two sequences.

\section{Conclusions}

The investigation demonstrates that extracting numerical data from ordinary, palynological preparations by means of electronic image analysis is both possible and useful.

It is shown that the size and shape of melanogen particles are not only dependent on the sedimentary texture of the actual sample but are also tied to the overall textural characteristics of the section. The size of the melanogen particle area projections increase upwards in a coarsening-upward sequence and their shapes become more rounded and less elongated.

Acknowledgements. Torsten Hoelstad expresses his sincere thanks to Jens Morten Hansen and Naja Mikkelsen for encouragement in the initial phase. Thanks to Heinke Andersen and Hanne Danielsen who swiftly and accurately typed the manuscript, to Jon Ineson who carefully corrected the English and Henrik Nøhr-Hansen and Martin Sønderholm for comments. The Danish Ministry of Energy is thanked for financial support.

\section{References}

Denison, C. \& Fowler, R. M. 1980: Palynological identification of facies in a deltaic environment. Proc. Sedimentation of North Sea reservoir rock, Geilo, Norwegian Petroleum Soc., Oslo sect. 12, 22 pp.

Fisher, M. J. 1980: Kerogen distribution and depositional environments in the Middle Jurassic of Yorkshire, U.K. Proc. 4th int. palynol. conf. Lucknow (1976-1977) 2, 574-580.

Hansen, J. M. \& Clausen, C. K. 1987: Palynofacies image analysis. In Brooks, J. \& Glennie, K. (ed.) Petroleum geology of North West Europe, 1213 only. Graham and Trotman.

Highton, P. 1990: The use of quantitative palynofacies studies for palaeoenvironmental analysis and correlation of Westphalian Sediments. Int. symposium to celebrate 25 years of palynology in the North Sea Basin, British Geol. Survey, Abstracts.

Hoelstad, T. 1986: Palynology of the Middle Jurassic Lower Graben Sand Formation of the U-1 well, Danish Central Trough. Danm. geol. Unders. A, 14, 25 pp.

Hoelstad, T. 1988: Characterization of kerogen by electronic image analysis. 7 th int. palynol. congress Brisbane. Abstracts, 73 only.

Hoelstad, T. 1989: Characterization of kerogen by electronic image analysis. Danm. geol. Unders., internal report 56, $44 \mathrm{pp}$.

Medalia, A. I. 1967: Morphology of aggregates. J. Colloid and Interface Sci. 24, 393-404.

Parry, C. C., Whitley, P. K. J. \& Simpson, R. D. H. 1981: Integration of palynological and sedimentological methods in facies analysis of the Brent Formation. In Illing, L. V. \& Hobson, G. D. (ed.) Petroleum geology of the continental shelf of North-West Europe, 205-215. London: Institute of Petroleum.

Piasecki, S., Christiansen, F. G. \& Stemmerik, L. 1990: Depositional history of an Upper Carboniferous organic-rich lacustrine shale from East Greenland. Bull. Can. Petrol. Geol. 38(3), 273-287.

Russ, J. C. 1986: Practical stereology, New York, London: Plenum Press, 185 pp.

Schwartz, H. 1980: Two-dimensional feature-shape indices. Mikroskopie (Wien) 37 (Suppl.), 64-67.

Stemmerik, L., Christiansen, F. G. \& Piasecki, S. 1990: Carboniferous lacustrine shale in East Greenland - additional source rock in the northern North Atlantic? In Katz, B. J. (ed.) Lacustrine basin exploration - case studies and modern analog. Am. Assoc. Petrol. Geol. Mem. 50, 277-286.

Tyson, R. V. 1984: Palynofacies investigation of Callovian (Middle Jurassic) sediments from DSDP site 534, BlakeBahama Basin, Western Central Atlantic. Marine and Petroleum Geology 1, 3-13.

Tyson, R. V. 1987: The genesis and palynofacies characteristics of marine petroleum source rocks. In Brooks, J. \& Fleet, A. J. (ed.) Marine petroleum source rocks. Spec. Publ. geol. Soc. Lond. 26, 47-67.

Tyson, R. V. 1989: Late Jurassic palynofacies trends, Piper and Kimmeridge Clay Formations, UK onshore and northern North Sea. In Batten, D. J. \& Keen, M. C. (ed.) Northwest European micropalaeontology and palynology, 135-172. Chichester: British Micropalaeontological Society Series.

Tyson, R. V. 1990: Kerogen image analysis: examples from the Late Jurassic of the North Sea. Int. symposium to celebrate 25 years of palynology in the North Sea Basin, British Geol. Survey, Abstracts.

Whitaker, M. F. 1984: The usage of palynostratigraphy and palynofacies in definition of Troll Field geology. Offshore Northern Seas - reduction of uncertainties in innovative reservoir geomodelling. Article C 6. Stavanger: Norsk Petroleumsforening. 